\title{
A PROPRIEDADE E A REGULAÇÃO DO SETOR ELÉTRICO BRASILEIRO E SUAS RELAÇÓES COM A EFICIÊNCIA DO SISTEMA
}

\author{
Frederico José Lustosa da Costa \\ Universidade Federal Fluminense, Brasil \\ fredlustosa@gmail.com \\ Vitor Yoshinara Miano \\ Instituto Federal Fluminense, Brasil \\ vitor.miano@iff.edu.br
}

\section{RESUMEN}

Este artículo examina la formación y el desarrollo del sector eléctrico brasileño. A partir de un estudio de caso en perspectiva histórica. se analiza la relación entre la intervención estatal y el tipo de mercado (monopólico, oligopólico, competitivo), el tipo de propiedad (pública o privada) y el crecimiento de la capacidad instalada del sector. El artículo muestra que el nacimiento del sector eléctrico brasileńo fue impulsado por iniciativas privadas, generalmente aisladas y pequeñas. Hasta la primera mitad del siglo XX, las acciones estatales en el sector eran puntuales. Posteriormente, hubo una fuerte presencia estatal en la planificación y operación del sistema. Gracias a ello, la regulación se hizo más efectiva. La crisis de la década de 1980 y las privatizaciones de la década de 1990 alteraron el modelo integrado, haciéndolo más competitivo. Los resultados, sin embargo, no fueron satisfactorios y, a partir de la década del 2000, se introdujeron nuevos modelos de cooperación entre los capitales público y privado. Las conclusiones destacan la relación existente entre la forma de propiedad y el desempeńo de las empresas eléctricas y el sector en su conjunto.

Palabras clave: Sector eléctrico, Nacionalización, Privatización, Estructuras de mercado, Brasil. 


\title{
OWNERSHIP AND REGULATION IN THE BRAZILIAN \\ ELECTRICITY SYSTEM AND THEIR RELATIONSHIP WITH THE SYSTEM'S EFFICIENCY
}

\begin{abstract}
This paper examines the creation and development of Brazil's electricity sector. Based on a case study from an historical perspective, it analyzes the relationship between state intervention, the type of market (monopolistic, oligopolistic, competitive), the type of ownership (state or private) and the growth of installed capacity. The paper shows that the sector had its origins in private initiatives that were, in general, small and isolated. Until the first half of the twentieth century, the state intervened only occasionally but, subsequently, played an important role in planning and operating the system. Thanks to this, regulation became more effective. The crisis of the 1980s and the privatizations of the 1990s changed the integrated model, increasing competition. However, the results were not satisfactory and, as from the first decade of this century, new models of cooperation between public and private capital were introduced. The conclusion section highlights the relationship that exists between type of ownership and the performance of electricity companies and the sector as a whole.
\end{abstract}

Keywords: Electricity sector, Nationalization, Privatization, Market structures, Brazil. 


\section{INTRODUÇÃO}

Desde o início de sua história, a nação brasileira segue um percurso sinuoso na busca do seu desenvolvimento, acompanhando em maior ou menor grau as transformaçóes políticas e econômicas mundiais e suas próprias forças endógenas. Entre essas forças, um foco recorrente de mudanças é o papel do Estado na vida econômica e social, particularmente na oferta de infraestrutura e na prestação dos serviços públicos.

Nesse contexto intervencionista, o sistema elétrico brasileiro apresenta um histórico bastante rico para o estudo dos movimentos de estatização e desestatização. $\mathrm{O}$ sistema nasceu dentro de uma estrutura concorrencial privada que, após algumas décadas, cresceu e se transformou em um oligopólio. Após a crise de 1929, com a assunção do keynesianismo e a intensificação da intervenção estatal, a regulamentação e as açóes governamentais passaram por mudanças significativas gerando reflexos no desenvolvimento da matriz energética brasileira. Com o passar do tempo, a planificação estatal acabou por alterar a estrutura desse mercado, tornando-o, devido à própria estrutura operacional do sistema, mais do que um monopólio estatal legal, um monopólio natural.

A crise econômica que se abateu sobre o país na década de 1980 abalou severamente o nível das inversôes públicas em infraestrutura. Com a crise institucional no setor elétrico, as pressóes do Fundo Monetário Internacional e a postura neoliberal do novo governo conduzido por Fernando Henrique Cardoso (1995-2002)tiveram início privatizaçóes de empresas de transmissão, geração e distribuição, assim como o desenvolvimento do regime regulatório para tutelar os serviços públicos concedidos. Os objetivos fundamentais eram a o ajuste fiscal do erário, a retomada dos investimentos para expansão da capacidade instalada e o estímulo à concorrência com vistas à reduçáo de custos e, consequentemente, preços.

No entanto, alguns resultados foram negativos. As tarifas cresceram acima da inflação, o risco energético aumentou, o Estado passou a ter altos gastos com a regulaçáa e as garantias de retorno ao capital privado, os investimentos não foram retomados, entre outros (Santos et al. 2008). A falta de sintonia entre a estrutura operacional do sistema elétrico brasileiro, predominantemente de matriz hidrelétrica e com alto grau de integração, não acomodou bem o sistema concorrencial implantado.

Coma mudançadegoverno em 2003, sob presidênciade Luis Inácio “Lula” da Silva (2003-2010), teve início uma nova fase do papel de coordenação e planejamento integrado por parte do Estado. Simultaneamente, foram 
aplicados novos modelos de cooperação, combinando capital privado e público. Alguns resultados positivos desta nova etapa já puderam ser identificados, como a retomada dos investimentos e a influência positiva do planejamento estatal na eficiência setorial. Em contraste, algumas debilidades também puderam ser observadas, como a manutenção do Estado como principal financiador dos empreendimentos de geração, distribuição e transmissão e a pequena influência na redução do ritmo de aumento das tarifas. Este tipo de atuação estatal, combinando capitais públicos e privados, vigorou até o impeachment da presidenta Dilma, em 2016.

Com relaçáo aos aspectos metodológicos, cabe resgistrar que o presente trabalho se caracteriza como um estudo de caso. Trata-se de um tipo de análise qualitativa de uso corrente nas ciências sociais aplicadas, que caracteriza, ao mesmo tempo, como um método de pesquisa e um recurso pedagógico (Bonoma 1985). Consiste em um exame aprofundado de uma situação particular que permite sistematizar dados de uma realidade social, preservando o a unidade do objeto estudado. É um adequado para responder às questóes "como" e "porque", relaçôes factuais que ocorrem ao longo do tempo, em situaçôes em que o método histórico ou o método experimental não são aplicados. Neste estudo em particular, o levantamento de dados ocorreu através de pesquisa documental e bibliográfica, partindo de uma análise em perspectiva histórica.

Além desta introdução, o artigo está dividido em mais seis seções. O segundo capítulo trata da formação do sistema elétrico a partir de iniciativas de empresas particulares no final do século XIX, geralmente isoladas e de pequeno porte. $\mathrm{O}$ capítulo seguinte analisa o crescimento do setor, capitaneado por empresas estrangeiras que concentraram grande participação neste mercado. Nesta etapa, as açóes governamentais ainda eram escassas e surtiam pouco efeito prático. A quarta seção aborda o período de maior crescimento quantitativo e qualitativo do setor, sob planejamento e execuçáo estatais. Nesta fase, o Estado passou a ser o controlador do sistema a regulação se tornou mais efetiva. Na quinta parte, o artigo discorre sobre as mudanças ocorridas, principalmente nas diretrizes do sistema elétrico, passando de um modelo integrado para um competitivo. Por fim, na conclusão, são destacadas algumas relaçôes entre a forma de propriedade e o desempenho das empresas de serviços públicos de energia, assim como do próprio setor como um todo. 


\section{ESTRUTURAS DE MERCADO}

Para analisar a formação do setor elétrico brasileiro, é preciso focar nas características essenciais desse mercado. Os critérios de avaliaçáo são a estrutura de mercado (monopolista, oligopolista, concorrencial perfeito ou imperfeito) e a forma de propriedade (privada ou pública). No caso brasileiro, como será exposto, estas estruturas e suas respectivas formas de propriedade possuem relação direta com os prognósticos de desempenho e expansão do sistema elétrico.

Para entender como os mercados funcionam devemos compreender a relação entre os dois lados fundamentais de qualquer mercado - oferta e demanda. A quantidade de ofertantes e demandantes, a capacidade de influenciar o mercado, entre outros fatores, ajudam a determinar o modo como o mecanismo do mercado atua na economia (Samuelson e Nordhaus 1998).

Uma das categorizaçôes fundamentais são as distinções entre mercados de concorrência perfeita, mercados de concorrência imperfeita e monopólios. Em concorrência perfeita os produtos oferecidos são homogêneos (o que não gera preferências por parte do consumo), as firmas são pequenas em relação ao mercado (de modo a não possuírem a capacidade de afetar os preços de mercado por decisão própria), não existem assimetrias de informações, entre outras características. Apesar de, teoricamente, os mercados perfeitamente competitivos serem os mais eficientes, economias reais e desenvolvidas incorporam diversas falhas de mercado tais como externalidades, barreiras de entrada, assimetrias de informação e custo de escala (Samuelson e Nordhaus 1998).

Com isso, o uso da concorrência perfeita como referencial para este trabalho perde adequação. Em contrapartida, as estruturas de concorrência imperfeita - oligopólio e concorrência imperfeita - e monopólio, que por sua vez incorporam as falhas de mercado tanto em sua constituiçáo como nos mecanismos de análise, se tornam mais produtivas para os fins deste trabalho. Os motivos para tal seráo discriminados a seguir.

A primeira falha de mercado que impede a ocorrência de concorrência perfeita ao desenvolvimento do sistema elétrico brasileiro são as barreiras de entrada, tanto legais como econômicas. Após um determinado grau de desenvolvimento do setor no Brasil, como será exposto, o alto custo de inversão característico dos subsistemas de distribuição, transmissão e geração elétrica atuaram e atuam para desencorajar potenciais entrantes no mercado. Isso interfere diretamente no grau de controle de preços 
praticados pelas firmas já participantes do mercado, tornando-o um mercado imperfeito. Esta barreira é tão grande que mesmo quando o Estado buscou reinserir a gestáo e propriedade privadas no sistema foram necessários maciços financiamentos públicos para amenizar esta barreira (Pinto, Godoy e Ribeiro 2011).

Economias de escala são as barreiras de mercado mais comuns e ajudam a determinar quantas firmas o mercado pode suportar e o tamanho destas (Samuelson e Nordhaus 1998). Caso estas economias existam, uma firma pode reduzir seus custos médios expandindo o volume de produção. Isso significa que firmas maiores possuirão vantagens em sua estrutura de custos em relaçáo à firmas menores e, conceitualmente, quando isto ocorre uma ou mais empresas buscam expandir sua produção ao ponto em que produziráo todo ou quase todo o volume ofertado no mercado. Assim sendo, indústrias dotadas destas economias de escala tendem a se oligopolizar (Samuelson e Nordhaus 1998).

Em segundo lugar, cabe mencionar que, no Brasil, ainda sobre as barreiras de mercado, além do aspecto econômic, durante décadas, o sistema foi operado e gerido pelo Estado (Brasil 1961, Lustosa da Costa, Miano 2013). Assim sendo, os mecanismos de autoregulação esperados em mercados de concorrência perfeita nunca se aplicaram.

O termo oligopólio significa "poucos vendedores" (Samuelson e Nordhaus 1998). Sua característica mais relevante é que neste mercado uma firma pode, individualmente, afetar os preços de mercado. No Brasil, o desenvolvimento inicial do setor elétrico foi carcterizado por um número muito pequeno de produtores de energia privados, que possuíam significativa liberdade para determinar os preços, não só pela pouca concorrência como pela imaturidade do mercado, marcado pela falta de oferta. Cabe destacar que as mudanças estruturais no sistema elétrico brasileiro, como poderá ser visto, ocorrem fundamentalmente no lado da oferta. De onde vieram os recursos para investimentos, quem investiu, que gerencia os ativos, são estas as questôes essenciais deste estudo.

Com base neste referencial, assim como nos impactos da propriedade serem de natureza pública ou privada, procede-se a análise do desenvolvimento do setor elétrico brasileiro - em especial a geração.

\section{A FORMAÇÃO DO SETOR ELÉTRICO BRASILEIRO}

Nas décadas finais do século XIX, o Brasil teve suas primeiras experiências com a geração e uso de eletricidade em larga escala. A cidade do Rio de 
Janeiro, até então a capital do país, já contava com serviços de iluminação pública fazendo o uso de dínamos como fontes geradoras na estação central da ferrovia Dom Pedro II, atual Central do Brasil.

Entretanto, pode ser considerado como o marco inicial do sistema elétrico brasileiro a operação da primeira central geradora termoelétrica situada na cidade de Campos dos Goytacazes, no Estado do Rio de Janeiro. Com capacidade de 52 kilowatts (kW), esta usina utilizava o vapor gerado em uma caldeira a lenha. A partir de então, enquanto o uso da eletricidade como força motriz para os serviços de iluminação e transporte públicos crescia, os setores produtivos passavam a adotar esta inovação tecnológica (Gomes et al. 2002).

Em 1883, foi construída a primeira hidrelétrica nacional em Diamantina, estado de Minas Gerais. A energia gerada era utilizada para acionar os equipamentos de mineração de diamantes. Na mesma década e no mesmo estado, mais duas hidrelétricas entraram em operação com a finalidade de sustentar processos produtivos de mineração ou de tecelagem (Gomes etal. 2002).

Já o fornecimento de energia a consumidores particulares teve seu início em Porto Alegre no Rio Grande do Sul com a Companhia Fiat Lux. A energia era gerada em uma termelétrica com capacidade de $160 \mathrm{Kw}$ (Gomes et al. 2002).

Entre 1883 e 1900 a capacidade instalada do Brasil passou de $61 \mathrm{~kW}$ para $10.850 \mathrm{~kW}$, sendo $53 \%$ de origem hidráulica (Gomes et al. 2002), existindo doze usinas com capacidade acima de $1000 \mathrm{hp}$. Tanto estas unidades como as usinas de menor capacidade eram de propriedade de concessionários e pequenos produtores que geravam energia para seu próprio consumo. Ou seja, até então a estrutura do mercado de geração elétrica era essencialmente privada e pulverizada.

Neste período, com relação à regulamentação do setor, destacam-se a Lei 1.145 de 1903 e o Decreto 5.704 de 1904, que dispunham sobre a concessão de serviços de eletricidade destinados ao suporte a serviços públicos providos pela Uniáo. Devido à composição do sistema elétrico vigente, composto majoritariamente por empresas privadas de pequeno porte, esta regulamentação teve pouca eficácia (Gomes e Vieira 2009).

No entanto, esta iniciativa manifestava o início de uma intenção do governo federal em coordenar o sistema, promovendo por via administrativa ou concessóes o uso do potencial hidráulico brasileiro para 
serviços públicos.

A primeira grande usina foi construída pela empresa Rio de Janeiro Tramway, Light \& Power Company, no município de Lajes no Estado do Rio e Janeiro. Inaugurada em 1907, contava com a potência inicial instalada de $12.000 \mathrm{~kW}$ e, através de obras de ampliação, alcançou em 1913 a capacidade nominal de $43.000 \mathrm{~kW}$. Isto a colocava como uma das maiores usinas do mundo e a maior do Brasil, representando cerca de 20\% da capacidade instalada nacional em 1909 (Gomes et al. 2002).

Entre 1907 e 1909 ocorreu uma intensificação do potencial hidráulico nos estados do Rio de Janeiro e Sáo Paulo, gerando um crescimento de 600\% na capacidade instalada do país (Gomes et al. 2002). Em 1924, uma subsidiária da Bond and Share Company, a American Foreign Power Company (Amforp), se instalou no país, comprando várias pequenas concessionárias no interior de Sáo Paulo. Seguindo com sua política de expansão via aquisiçôes, esta empresa operava em mais nove capitais e três cidades de relevância para as áreas metropolitanas (Gomes et al. 2002).

A partir de 1930, a maioria das atividades do setor elétrico estava sob controle das empresas de capital estrangeiro Amforp e da Light. Logo, mantinha-se a predominância do capital privado como proprietário e investidor no sistema. No entanto, em contraste com o período anterior, a estrutura do mercado se tornara oligopolizada. Sob o aspecto técnicooperacional, a geração já passara a ser predominantemente hidráulica, característica fundamental do sistema elétrico brasileiro até os dias atuais (Sauer et al. 2003).

No cenário econômico mundial, as mudanças após a crise de 1929 induziram a uma redefiniçáo do papel do Estado, refletindo num crescente intervencionismo na economia. A partir de 1934, os contratos com os municípios, estados e distrito federal passaram a ser legislados e outorgados pela União. A promulgação do Código das Águas - Decreto 24.643 de 1934 - submetia ao regime de concessóes e autorizações a exploração de energia hidráulica, assim como a transmissão, distribuição e transformação.

Foram proibidas a aquisição e incorporação de empresas do setor elétrico, no intuito de cessar a expansão do oligopólio controlado pela Light e Amforp. $\mathrm{O}$ interesse de nacionalização mostrava-se evidente no artigo 195 do Código das Águas, que dispunha: "Autorizaçôes ou concessôes serão conferidas exclusivamente a brasileiros ou a empresas organizadas no Brasil”. 
Os resultados foram distintos dos obtidos com a Lei 1.145 de 1903 e o Decreto 5.704 de 1904. A intervenção estatal passou a efetiva, devido ao interesse federal em desenvolver a indústria nacional. A necessidade de expansão, tanto em termos de capacidade instalada como de abrangência geográfica, demandava grandes inversôes financeiras e o planejamento integrado do sistema elétrico.

\section{EXPANSÃO E CONSOLIDAÇÃO DO SISTEMA}

Após o fim do primeiro governo de Getúlio Vargas (1930-1945), a intervenção estatal foi intensificada, não somente na regulação e fiscalização, mas também nas inversóes e na operação. Neste período havia grande centralização das decisóes na esfera federal, no entanto, a estrutura do mercado ainda oferecia resistências às vontades do governo, num momento em que o setor elétrico ganhava cada vez mais relevância para o projeto desenvolvimentista nacional (Gomes e Vieira 2009).

Essa mudança inaugura uma nova etapa na estrutura do mercado. No seu início, o setor elétrico era uma estrutura concorrencial com agentes econômicos privados de pequeno porte, passando para um oligopólio também privado. Nestas duas etapas, além do Código das Águas, pouco participou o Estado na coordenação do sistema ou na realização de inversôes.

O novo estágio da industrialização brasileira, de substituição de importaçóes centrada no mercado interno, dependia de mudanças estruturais para viabilizar o desenvolvimento da indústria pesada, bens intermediários e de capital. Em 1956, no governo de Juscelino Kubitschek (1956-1961), o país passou por uma aceleração em seu crescimento econômico, tendo o setor elétrico prioridade nas decisóes federais. Muitas usinas hidrelétricas foram construídas assim como a segunda empresa federal de energia, Furnas. Ademais, grande parte das empresas de energia elétrica estaduais foi fundada (Gomes et al. 2002).

Este governo teve como principal instrumento de planejamento econômico o Plano de Metas que em seus investimentos previstos direcionava $43,4 \%$ dos recursos para a área energética, sendo $23,7 \%$ para projetos de eletricidade. $\mathrm{O}$ projeto desenvolvimentista traçou a meta de crescimento da capacidade instalada de geração de 3.148 megawatts (MW) em 1955 para 5.595 MW ao final do período. Apesar de náo alcançar integralmente a meta, a execuçáo do plano foi um sucesso ao atingir $84 \%$ da expansão prevista em apenas cinco anos. Entre 1946-1962 a capacidade instalada cresceu 326,9\% (CNBCME 2002). 
Em síntese, o período entre 1946 e 1962 - criação da Empresa Mista Centrais Elétricas Brasileiras S.A. (Eletrobrás) - foi marcado por uma alteração profunda no modelo brasileiro de desenvolvimento econômico, privilegiando a participação do Estado em funçôes produtivas, financeiras e planificadoras (Gomes et al. 2002: 8).

Com o início das atividades da Eletrobrás em 1962 a institucionalização do sistema mudou radicalmente. A partir de então, esta estatal gerenciava o funcionamento isolado de cada usina geradora sob seu controle como também administrava o sistema com um todo, promovendo sua integração. Também planejava o crescimento do sistema ao longo prazo, alinhando os investimentos numa perspectiva nacional. Com isso, os novos empreendimentos tinham maior probabilidade de integração com a capacidade já existente, potencializando os ganhos e reduzindo riscos. Este planejamento centralizado persistiu por décadas e a sinergia obtida permitiu que o sistema elétrico brasileiro se tornasse um dos sistemas mais baratos, confiáveis, flexíveis e ambientalmente limpos dentre as grandes potências mundiais (Santos et al. 2008).

O golpe militar de 1964 instaurou uma nova fase na política brasileira. No governo, os militares se preocupavam com questóes relativas à soberania nacional, incluída, entre suas prioridades o setor elétrico. $\mathrm{O}$ apoio político e econômico em conjunto com a disponibilidade de recursos financeiros externos permitiu que o governo ampliasse sua participação, via empresas estatais. Em 1964 a Eletrobrás comprou todas as empresas que compunham o grupo estrangeiro Amforp e, em 1979, também comprou a empresa, decretando de vez o fim do oligopólio que vigorou nas primeiras décadas do século (Gomes e Vieira 2009).

Foi construída a Itaipu Binacional, usina controlada pelo Brasil e pelo Paraguai, com sua fração brasileira controlada pela Eletrobrás. Em 1973, a Lei de Itaipu ampliou o papel de planejamento e financiamento da holding no cenário nacional, ao repassar o controle de geradoras estaduais para a Eletrobrás (Brasil 1973).

Institui-se a Reserva Global de Garantia, um fundo gerido para a Eletrobrás para que se pudesse oferecer a mesma tarifa a todos os consumidores em todo o território nacional. Esta política pública gerou reaçôes contrárias de alguns governos estaduais, principalmente aqueles que possuíam concessionárias com melhor desempenho financeiro. No entanto, a União detinha muita força e a medida foi implantada (Gomes e Vieira 2009). 
De acordo com o Centro da Memória da Eletricidade no Brasil (CMEB1995), entre 1962 a 1979, a capacidade instalada do Brasil cresceu $388,22 \%$. Ainda, o governo militar iniciou o programa nuclear brasileiro, apostando na nova matriz energética, construindo usinas no município de Angra dos Reis no Estado do Rio de Janeiro.

\section{ESTAGNAÇÃO E CRISE INSTITUCIONAL}

No início da década de 1980, o crescimento econômico brasileiro sofre uma grande redução. A desvalorização da moeda nacional incorreu na queda significativa nos níveis de investimento público, financiado com empréstimos externos. Neste contexto, a intervenção estatal foi redirecionada: se por décadas o intuito do governo era colocar o Estado e a política econômica em prol do desenvolvimento econômico e expansão da industrialização, a crise econômica fez com que o foco fosse transferido para o alcance de estabilidade. No plano microeconômico, ao final da década de 1970, o governo buscou conter a inflação. A sustentabilidade financeira das companhias mantinha-se viável e até 1977, quando a remuneração mínima legal era de 10\%. O Decreto 83.940, de 1979, estabeleceu que qualquer atualização no valor das tarifas deveria passar necessariamente pela prévia aprovação do ministro de Estado, chefe da Secretaria de Planejamento. $\mathrm{O}$ cálculo econômico-financeiro que determinava o valor das tarifas incorporara então fatores exógenos ao setor, incluído nestes o combate à inflação (Gomes e Vieira 2009).

Com isso, as finanças das empresas foram negativamente afetadas. Os desequilíbrios ocorriam tanto nos gastos correntes - o congelamento das tarifas impactou a lucratividade - como nas despesas de capital - a moratória do México, em 1982, suspendeu os empréstimos concedidos ao Brasil. As empresas do setor elétrico, já bastante endividadas de investimentos anteriores, foram obrigadas a adiar ou cancelar suas obras:

Com a interrupçáo de crédito dos organismos internacionais, o setor passou a ter fluxo negativo entre os empréstimos externos e o pagamento do serviço da dívida. O serviço da dívida, que correspondera a $20 \%$ das aplicaçóes setoriais em 1975, chegou a 50\% em 1985 (Gomes et al. 2002: 11).

A redemocratizaçáo do país e as mudanças institucionais decorridas da promulgação da Constituição Federal de 1988 tornaram os governos estaduais mais fortes. Com isto, as empresas de distribuição ganharam autonomia para adiar os pagamentos dos tributos e também o pagamento para as geradoras de energia federais. Não somente a inadimplência afetou 
os gastos correntes, como ainda o governo aumentou a alíquota do imposto de renda para as empresas do setor elétrico, de 6\% para 40\% (Gomes et al. 2002).

Em 1990 o Estado passava por uma crise fiscal grave, sem recursos para realizar investimentos, não somente no setor elétrico, mas em quase todos os setores de infraestrutura. Como resultado, De 1979 a 1992 a capacidade instalada do país cresceu 120,31\% (cCBCME 2002).

A reduçáo do ritmo de investimentos permitiu que um crescimento superior do consumo de energia elétrica em relação ao crescimento da capacidade instalada. Este quadro auxiliou a implantação da nova perspectiva econômica adotada pelo novo presidente, Fernando Collor (1990-1992), que viu como saída para a retomada do crescimento no setor a privatização das empresas públicas.

\section{DESESTATIZAÇÃO}

Apesar das intençôes de Fernando Collor, turbulências no cenário político forçaram a saída prematura deste do governo. Após o seu impeachment em 1992, o Vice-Presidente Itamar Franco (1992-1994) lidava com um cenário de dificuldades no setor elétrico. Uma de suas primeiras iniciativas foi atuar sobre a regulação, através da Lei 8.631 de 1993, redefinindo os modelos de composição das tarifas e facilitando a conciliação patrimonial entre credores e devedores do setor, amenizando a situação no curto e médio prazo (D’Araújo 2009).

Com a ascensão de Fernando Henrique ao poder em 1995 um direcionamento neoliberal foi formalmente assumido pelo governo. Em seu primeiro ano de mandato foi promulgada a Lei das Concessóes (Lei 8.987 de 1995), dispondo sobre a concessão e permissão de serviços públicos, incluindo os serviços de energia elétrica.

A Agência Nacional de Energia Elétrica (Aneel) foi criada em 1996 (Lei 9.427), após algumas privatizaçôes relevantes já ocorridas. Ainda, o modelo setorial proposto pelo Ministério de Minas e Energia ainda náo estava consolidado. A implantaçáo do novo regime regulatório para os serviços públicos concedidos foi problemática no Brasil, mesmo no setor elétrico, menos afetado do que outros setores tais como o de infraestrutura rodoviária (Miano e Lustosa da Costa 2013).

As novas agências reguladoras criadas, entre estas a Aneel, não herdaram conhecimentos, experiências e competências de outras organizaçóes, 
necessárias para o desempenho destas novas funções estatais de regulação. Isto dificultava o alcance do equilíbrio em um dos problemas centrais da regulação de serviços públicos, que é mensurar a apropriação privada do bem social, garantindo a dimensão social embutida no serviço assim como as necessidades da remuneraçáo de capital dos investidores (Miano e Lustosa da Costa 2013).

O novo modelo do setor elétrico refletia uma mudança na perspectiva com a qual se avaliava a energia elétrica. Antes, a concepção era de energia como um bem social, o qual o Estado buscava assegurar por meio de um serviço estatal cooperativo. Após, a energia era considerada mercadoria regida pelas leis de oferta e demanda - sob o viés da lucratividade, a ser fornecido por um modelo concorrencial (Gomes e Vieira 2009).

Operacionalmente, um grau significativo de integração entre as empresas de geração, distribuição, transmissão, comercialização e operação. A nova modelagem do sistema quebrava a verticalização da cadeia produtiva energética, devido ao pressuposto de que a relaçáo entre ganhos de eficiência e a concorrência seria sempre positiva. No entanto, duas das principais justificavas das privatizaçôes - a redução das tarifas e do risco energético - não se verificaram (Sauer et al. 2003).

A partir de 1999, a escassez de chuvas impactava severamente a geração de energia. Em 2001, emergencialmente, o governo federal criou a Câmara de Gestáo da Crise de Energia. A falta de planejamento integrado para o setor intensificou os prejuízos da crise energética, culminando no racionamento energético, equivalente a $25 \%$ do consumo (até então, o maior racionamento da história mundial em tempo de paz) (Santos et al. 2008).

Ainda em 2001, o coordenador da Câmara de Gestão da Crise de Energia criou uma empresa estatal com escopo na obtenção de energia de forma emergencial. Esta organização compraria energia dos investidores que construíssem termelétricas, independente da demanda. O que ocorreu é que, quando estas novas usinas entraram em operação o nível das chuvas retornou a índices de frequência e volume satisfatórios, e os reservatórios das hidrelétricas voltaram a se abastecer satisfatoriamente. Com isso, a energia destas novas geradoras náo era demandada, enquanto o pagamento aos investidores era assegurado (Etcheverry 2008).

Essa crise evidenciou o alto custo da introdução do sistema concorrencial em um sistema hidrelétrico operacionalmente integrado, que responde à quase totalidade da oferta de energia elétrica no país (Sauer et al. 2013). 
Como alternativa, surgiu a necessidade da introdução de outras fontes primárias na matriz energética, tendo em vista a vulnerabilidade decorrente da forte dependência da matriz hidrelétrica. Como o Brasil se coloca como um dos maiores produtores mundiais de álcool de cana, uma alternativa seria gerar excedentes para a geração elétrica.

Também, a alternativa do gás natural apresentava grande viabilidade, tanto pela expansão das reservas nacionais como pela operação do gasoduto Brasil-Bolívia. Ademais, ainda havia boas possibilidades de cooperação com a Argentina, Peru, Bolívia e Venezuela, países fronteiriços dotados de grandes reservas.

Ao final de 2002 muitas empresas de distribuição já haviam sido privatizadas. No entanto, a geração e transmissão ainda eram executados por empresas estatais, a maioria sob controle da Eletrobrás. Só não foram privatizadas as distribuidoras dos estados de Piauí, Rondônia, Acre, Alagoas e Amazonas, pouco atraentes financeiramente - baixas receitas correntes e grandes necessidades de investimentos no sistema.

De 1992 a 2002, a capacidade instalada do país cresceu 36,17\%, refletindo assim a falta de investimento tanto privado como público (CBCME 2002). A confiabilidade do sistema foi afetada, e, mesmo após reformas, o sistema segue dependendo esporadicamente de planos emergenciais (Santos et al. 2008).

\section{RETOMADA DA INTERVENÇÃO ESTATAL E NOVOS MODELOS DE GESTÃO}

Na década de 1990 o governo passou a apostar no auto regulação por parte do mercado e na esperança de inversóes por parte do capital privado, intensificando as privatizaçóes e concessóes. Em contrapartida, desenvolveu seu poder regulatório, incluindo a criação da Aneel.

A concorrência num sistema integrado como o brasileiro era restrita e de certo modo até desaconselhável, já que a estrutura nacional apresentava significativos ganhos de escala devido à sua integração (Sauer et al. 2013). Quando da ascensão de Luís Inácio Lula da Silva ao poder, já se reconhecera que o modelo centrado na autorregularão pelo mercado fracassou. A ineficácia da regulação estatal facilitava a sobreposição dos interesses privados sobre os interesses coletivos, tanto imediatos (altas tarifas) como de longo prazo (investimento para expansão da capacidade instalada) (Sauer et al. 2003). 
O novo governo de Luis Inácio "Lula" da Silva iniciou uma reorganização do sistema elétrico a partir de 2004. A energia pode ser explorada por quaisquer agentes com competências e recursos para tal, sob tutela e coordenação do governo federal, especificamente do Ministério de Minas e Energia. Este posicionamento de cooperação era evidente em alguns aspectos, como no fato de que os agentes privados teriam sua venda de energia assegurada desde que os empreendimentos estivessem de acordo com o planejamento feito pelo ministério. Os empreendimentos privados eram financiados com dinheiro público, em percentuais altos e juros baixos. Um mercado atraente, com modalidades de financiamento facilitadas e demanda assegurada.

Houve um aprimoramento dos processos licitatórios realizados para as concessóes. Nos leilóes executados no governo Fernando Henrique, por vezes os vencedores não tinham em mãos todos os requisitos para poderem iniciar as obras. Assim, os consórcios tinham obrigação de construir as usinas no prazo estipulado, mesmo sem ter obtido sequer a licença ambiental para iniciar as obras. O que, obviamente, trazia prejuízos. Já no governo Lula, no momento do leilão, a licença ambiental para o empreendimento já estava concedida, permitindo que o vencedor iniciasse as obras assim que possível (Pinto, Godoy e Ribeiro 2011).

Outra mudança diz respeito aos critérios para se vencer um leiláo. Anteriormente, ganhava a empresa ou consórcio que oferecessem a maior taxa de tarifa de uso do bem público, ou seja, aquela que remuneraria mais o Estado. Isto refletia no custo para o usuário, pois as empresas tenderiam a repassar este custo ao consumidor. Na nova perspectiva, seria considerado vencedor aquele que oferece a menor tarifa para o consumidor pelos trinta anos de concessão.

Uma nova modalidade de cooperação entre capital público e privado tomou corpo com a regulamentação das Parcerias Público-Privadas (PPP), regidas pela Lei 11.079 de 2004. No Direito brasileiro, estas são novas modalidades de concessão para contratos com valor igual ou superior a $\mathrm{R} \$$ 20.000.000. Antes mesmo da promulgação dessa lei já existiam algumas iniciativas pioneiras destas parcerias, estaduais, em obras de menor montante. Mas após a promulgaçáo da lei supracitada, obras de menor porte foram excluídas deste escopo.

No geral, a obra de infraestrutura é realizada e gerenciada pelo capital privado e deve, posteriormente, ter seus bens e direitos revertidos ao domínio do Estado. Este, por sua vez, pode optar por gerenciar o ativo ou entregar novamente sua administração a novos concessionários. No período 
no qual os bens ficam sob tutela do capital privado, fica a Administração autorizada a oferecer garantias para o cumprimento das obrigaçóes assumidas pelos agentes privados nas PPPs. No geral, a viabilidade destes projetos é avaliada em empreendimentos de infraestrutura essenciais e com urgência.

$\mathrm{Na}$ prática, o capital privado utilizou financiamentos públicos para as obras firmadas nas PPPs. De fato, grande parte das inversóes nas obras firmadas por PPPs eram de origem do Banco Nacional de Desenvolvimento Econômico e Social (BNDES). Se havia o interesse em aumentar o investimento em infraestrutura sem aumentar o endividamento estatal, pouco foi feito neste sentido (Pinto, Godoy e Ribeiro 2011). O que podemos diferenciar é que há um compromisso do capital privado com estas dívidas, mas o impacto do desembolso destes montantes recaiu sobre o Estado. Logo, não tanto na medida desejada, ocorreu um compartilhamento de riscos entre o capital privado e público.

Com relação aos requisitos para a remuneração do capital privado, os projetos de PPPs apresentavam uma diferença significativa na gestão da contraprestação pública sobre a tarifa do serviço concedido. Os acordos firmados pela durante o apagão de 2001 pela Câmara de Gestão da Crise de Energia garantiam o retorno sobre o investimento mesmo sem que houvesse efetivo usufruto do serviço. A nova regulamentação das PPPs autoriza a contraprestação após a efetiva disponibilidade do serviço licitado. E, de outro lado, para proteger o interesse privado, esta contraprestação pode ser realizada proporcionalmente a parcela fruível do serviço, ou seja, o objeto pode ser disponibilizado em etapas, oferecendo pagamentos proporcionais ao desempenho privado.

Outro avanço foi a instituição do valor mínimo de $\mathrm{R} \$ 20.000 .000$ para os contratos de parceria entre setor privado e público pode ser considerado um aprimoramento das práticas de gestáo pública. Num primeiro momento, considerando os problemas ocorridos com a implantação dos modelos de agências reguladoras e as diversas debilidades da Administraçáo Pública brasileira, poder-se-ia achar arriscado inovar justamente em contratos de valor táo alto. No entanto, a elevaçáo do piso para estes contratos reduz significativamente o número de obras e de consórcios, facilitando a posterior fiscalização e regulação, dois dos principais problemas ocorridos no desenvolvimento do regime regulatório das concessóes ocorridas na década de 1990 (Pinto, Godoy e Ribeiro 2011). 


\section{CONCLUSÃO}

Muito já se discutiu sobre a atuação do Estado desenvolvimentista brasileiro. Durante as décadas nas quais o governo adotava esta postura, as condiçóes econômicas nacionais iam de encontro com algumas das razões teóricas para este tipo de intervenção (Curutchet 2013). Havia o interesse do desenvolvimento via industrialização, a imaturidade de muitos setores produtivos estratégicos de infraestrutura, a necessidade de grandes investimentos com longo prazo de payback, etc.

A saída proposta pelos últimos governos brasileiros demonstra que, mesmo em setores já institucionalizados, o capital privado não realiza as inversóes de maior porte tai como a construção de hidrelétricas. Por isso então há grande participação de recursos públicos nas PPPs, que financiam os investimentos privados. De fato, a responsabilidade pelo pagamento da inversão é do capital privado, mas o impacto orçamentário é absorvido pelo Estado, que dilui o investimento para o capital privado:

Considerando que los gobiernos locales estadounidenses se aferran con firmeza a la provisión pública del agua, ¿deberían los países menos desarrollados optar por la privatización? Cuando la capacidad de regulación es más débil, ¿existe una racionalidad para privatizar el agua? (Florio 2013).

Essa é uma questáo perfeitamente cabível quando avaliamos o regime regulatório implantado a partir da década de noventa no Brasil. Com maiores ou menores problemas em cada setor, mas no geral, ineficiente, a regulação dos serviços públicos deixa a desejar (Lustosa da Costa e Miano 2013; Santos et al. 2008). Quanto ao setor elétrico, o reflexo mais nítido é a elevação das tarifas após as privatizações. Ainda, cabe destacar que o modelo regulatório busca a inclusão do usuário do serviço público como stakeholder, no entanto, oferece poucas possibilidades de participação efetiva deste grupo como atores políticos (Cavalcanti e Peci 2001).

Poderíamos contra-argumentar afirmando que a elevação nos custos é fruto do modelo de concorrência simulada adotado, que até hoje não se enquadra na estrutura operacional integrada de um sistema predominantemente hidrelétrico. Isto é verdade, mas nos levaria a criticar a própria condução das privatizaçóes. No debate entre privatistas e estatistas pode-se, ao menos, chegar ao consenso de que o aumento de eficiência de um setor não possui relação causal necessariamente positiva com a gestão privada. No histórico exposto, pode-se perceber que o risco energético aumentou, as crises são mais frequentes, o custo ao usuário se tornou um 
dos maiores do mundo - considerando as grandes nações-, o custo ao erário é alto - para manter a concorrência simulada, garantir retorno dos investidores e financiar grande parte dos investimentos privados.

Com o processo de impeachment da presidente Dilma Roussef e a posse de Michel Temer, um programa de governo de natureza liberal abriu novos horizontes para o setor elétrico. Este fat demarcou uma mudança política significativa no governo federal, que se apresenta como uma necessidade para estudos subsequentes que objetivem compreender melhor as mudanças estrutirais do sistema elétrico brasileiro e suas consequências.

No dia 21 de agosto de 2017, o Ministério de Minas e Energia anunciou a privatizaçáo da Eletrobrás com a venda de uma grande parte de suas ações. O governo, que contou com o apoio parlamentar para realizar suas reformas, autorizou a venda dos distribuidores de energia controlados pela Eletrobrás por meio do decreto presidencial em 6 de novembro de 2017.

O Edital do Leiláo No 02 de 2018 do Programa de Parcerias de Investimentos, integrado ao Programa Nacional de Desestatizaçáo, publicizou o processo licitatório para transferência do controle acionário de seis distribuidoras de energia subsidiárias da Eletrobrás: Companhia Energética do Piauí (Cepisa); Companhia Energética de Alagoas (Ceal); Companhia de Eletricidade do Acre (Eletroacre); Centrais Elétricas de Rondônia (Ceron); Boa Vista Energia S.A. e Amazonas Distribuidora de Energia S.A.

Em agosto de 2018 três destas distribuidoras já foram arrematadas: Ceron, Eletroacre e Boa Vista Energia. A consolidação do movimento de desestatização também defendido pelo presidente eleito Jair Bolsonaro e sua equipe econômica, governo que irá assumir a presidência a partir de 2019, indica que mudanças estruturais no sistema elétrico brasileiro seguirão ocorrendo na mesma direção. 


\section{REFEREANCIAS}

Bonoma, T. V. (1985). Case Research in Marketing: Opportunities, Problems, and Process. Journal of Marketing Research, 22 (2), 199-208.

Cavalcanti, B. e Peci, A. (2001). A Outra Face da Regulação: O CidadãoUsuário De Serviços Públicos no Novo Modelo Regulatório Brasileiro. XXV Encontro da Associação Nacional de Pós-graduação em Administração, Campinas, 16 a 19 de setembro de 2001.

Centro da Memória da Eletricidade no Brasil (CMEB) (1995). A Eletrobrás e a História do Setor de Energia Elétrica no Brasil. Rio de Janeiro: Centro da Memória da Eletricidade no Brasil.

Comitê Brasileiro do Conselho Mundial de Energia (2002). Boletim Anual: Estatistica Brasileira de Energia. Rio de Janeiro: Comitê Brasileiro do Conselho Mundial de Energia.

Curutchet, A. S. (2013). Razones Teóricas Para La Existencia de las Empresas Del Estado. En Chavez e Torres (Eds.), La Reinvención Del Estado Empresas Públicas y Desarrollo em Uruguay, América Latina y el Mundo. Montevideo: Transnational Institute, ANTEL y MIEM-DNI.

D`Araújo, R. P. (2009). O Setor Elétrico Brasileiro - Uma Aventura Mercantil. Brasília: Confea.

Etcheverry, M. S. (2008). Privatização do Setor Elétrico Brasileiro: Impactos sobre o Trabalho. Revista Labor, 1, 1-15.

Florio, M. (2013). Repensar la Empresa Pública: La Nueva Agenda de Investigación. En Chavez e Torres (Eds.), La Reinvención del Estado: Empresas Públicas y Desarrollo em Uruguay, América Latina y el Mundo. Montevideo: Transnational Institute, ANTEL y MIEM-DNI.

Gomes, A. C. S., Albarca, C. D., Faria Eliada, S. T. e Fernandes, H. H. (2002). BNDES 50 Anos - Histórias Setoriais: O Setor Elétrico. Rio de Janeiro: BNDES.

Gomes, J. P. P. e Vieira, M. M. F. (2009). O Campo da Energia Elétrica no Brasil de 1880 a 2002. Revista de Administração Pública, 43 (2), 295-321. 
Lustosa da Costa, F. e Miano, V. Y. (2013). Estatitazação e Desestatização no Brasil: O Papel das Empresas Estatais nos ciclos da Intervenção Governamental no Domínio Econômico. Revista de Gestión Pública, 2 (1), 145-181.

Miano, V. Y. e Lustosa da Costa, F. (2013). Agetransp e a (Deficiente) Fiscalização das Barcas S/A: Uma Análise da Atuação da Agência no seu Papel de Principal da Concessão Aquaviária Fluminense. ENANPAD - Encontro da ANPAD, Rio de Janeiro, v. 37, APB 1647, CD.Rom.

Pinto, F. L. B., Godoy, R. W. e Ribeiro, D. B. C. (2011). Parceria PúblicoPrivada: Uma Experiência em Construção. Caderno de Estudos Ciência e Empresa, 8, 66-78.

Samuelson, P. e Nordhaus, W. (1998). Economics. Boston, Mass: Irwin/ McGraw-Hill.

Santos, G., Barbosa, E., Silva, J., Abreu, R. (2008). Por Que as Tarifas Foram para os Céus? Propostas para o Setor Elétrico Brasileiro. Revista do BNDES, 29, 435-474.

Sauer, I. L., Rosa, L. P., Araujo, R. P., Carvalho, J. F., Terry, L. A. e Prado, L. T. S. (2003). A Reconstrução do Setor Elétrico Brasileiro. Campo Grande, MS: Ed. UFMS; São Paulo: Paz e Terra.

Legislação

Brasil. (1961). Lei no 3.890-a, de 25 de abril 1961. Diário Oficial da União. Brasília, DF: Presidência da República.

Brasil. (1973). Lei no 5.899, de 5 de julho de 1973 - Lei de Itaipu. Diário Oficial da União. Brasília, DF: Presidência da República.

Recibido: 04-01-2018

Aceptación de la versión final: 22-11-2018 